\title{
Direct ethanolic extraction of polar lipids and fractional crystallization from whey protein phospholipid concentrate
}

\author{
Quintin Ferraris (1) and Michael C. Qian* (1)
}

\section{Graphical Abstract}

Whey Protein Phospholipid

Concentrate (WPPC)

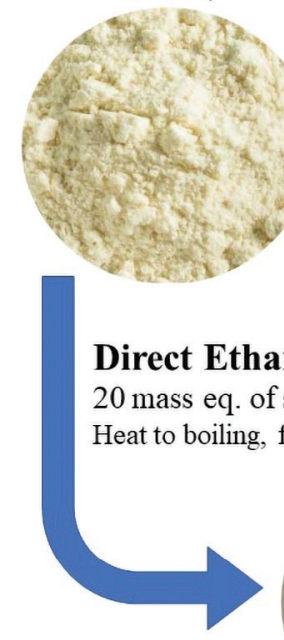

Total lipid extract residue

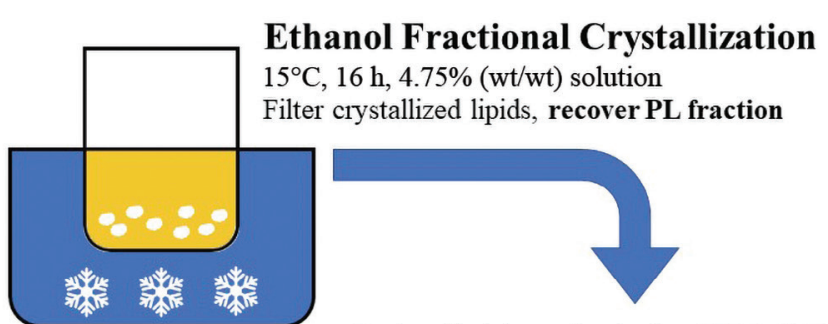

Polar lipid analysis by HPLC-ELSD

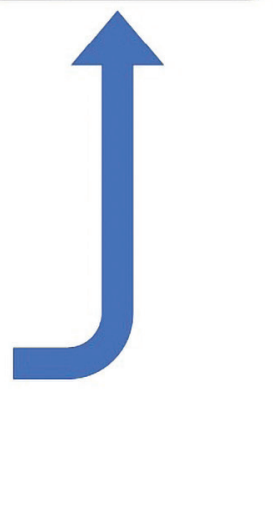

(38.6\% PL by mass)

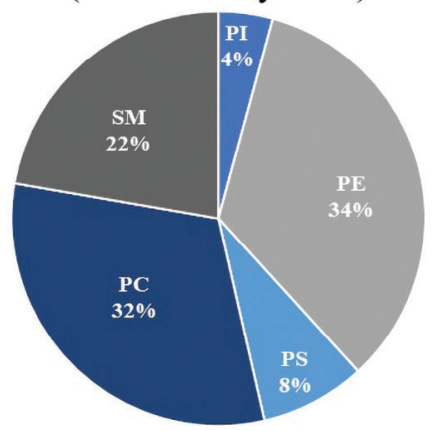

\section{Summary}

A method for dairy lipid extraction using ethanol as a food-grade solvent was developed with pilot-scale and industry applications in mind. A total lipid extract was recovered from whey protein phospholipid (PL) concentrate using 20 mass equivalents (eq.) of absolute ethanol heated at a boiling point. Precipitated protein solids were filtered out and solvent evaporated from the recovered filtrate. Additional investigations into the potential of ethanol-based fractional crystallization for the purification of polar lipids from triglyceride content showed limited effects. Total extract lipids were dissolved in the ethanol extraction solvent at a concentration of $4.75 \%\left(\mathrm{wt} / \mathrm{wt}\right.$ ) and allowed to crystallize at $15^{\circ} \mathrm{C}$ for $16 \mathrm{~h}$ before being analyzed by HPLCelectrospray light scattering detection (ELSD). The resulting crystallized lipids (phosphatidylinositol, Pl; phosphatidylethanolamine, PE; phosphatidylserine, PS; phosphatidylcholine, PC; sphingomyelin, SM) were filtered away from the ethanol-soluble polar lipid fraction. The final resulting lipid residue was determined to be $38.6 \%$ polar lipids by mass, with an increase of $<1 \%$ from the total lipid extract. However, the concentration of SM was increased by the fractional crystallization process..

\section{Highlights}

- Ethanol can be used to extract polar lipids directly from whey powders.

- The extraction method avoids specialty equipment and expensive instrumentation.

- The resulting lipid residue was determined to be $38.6 \%$ phospholipids by mass ( $10 \%$ SM by mass).

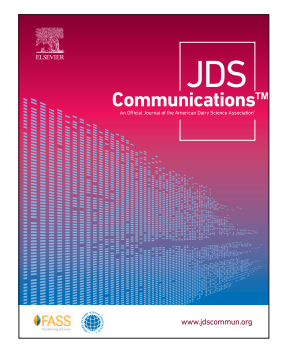

Department of Food Science and Technology, Oregon State University, Corvallis 97330. *Corresponding author: michael.qian@oregonstate.edu. @ 2021, The Authors. Published by Elsevier Inc. and Fass Inc. on behalf of the American Dairy Science Association ${ }^{\circledast}$. This is an open access article under the CC BY license (http://creativecommons.org/licenses/by/4.0/). Received January 05, 2021. Accepted March 13, 2021. 


\title{
Direct ethanolic extraction of polar lipids and fractional crystallization from whey protein phospholipid concentrate
}

\author{
Quintin Ferraris (1) and Michael C. Qian* (1)
}

\begin{abstract}
Polar lipids, including sphingomyelin (SM) and other sphingolipids, have nutritional implications in many important metabolic pathways. Milk and whey are valuable sources of these bioactive lipids, differing in SM content compared with other plant-based lecithins in the food industry. Dairy lipids were extracted from whey protein phospholipid concentrate powder by direct exposure to a food-grade solvent, ethanol. A total of 20 mass equivalents of solvent was required to completely recover all lipid material of the original whey protein phospholipid concentrate sample. Using a minimal apparatus, absolute ethanol, and heating to a boiling point, a final total lipid extract composed of 37.7\% phospholipids (PL) by mass was achieved. The method was developed with potential pilot-scale and industry application in mind. Investigations into fractional crystallization showed limited success at purifying PL from triglyceride content $(<1 \%$ increase in percent PL by mass). However, the relative percentage of SM was increased in the fractionated sample compared with the total lipid extract. Fatty acid analysis of the PL fraction reported a composition of 33.3\% monounsaturated fatty acids and $9.8 \%$ polyunsaturated fatty acids. Additional work is needed to investigate different conditions for lipid recovery, PL recovery, and PL purification by fractional crystallization in ethanol.
\end{abstract}

$P$ olar lipids are a valuable nutraceutical and serve a critical role in the food industry as a functional ingredient. Polar lipids, including phospholipids (PL) and sphingolipids (SL), are found in dairy as organized membrane structures surrounding fat globules (Lopez et al., 2014; Singh and Gallier, 2017). The milk fat globular membrane (MFGM), containing the polar lipids and bioactive proteins, has evolved to benefit infant development. Polar lipids are required for many aspects of infant development, including organ growth and cellular replication (Cilla et al., 2016) and neurobehavioral development (Tanaka et al., 2013). Additional studies have shown the health benefits of milk polar lipids in adults, including significantly reducing lipid cardiovascular markers with reducing cholesterol absorption (Vors et al., 2019).

Attempts at industry-scale isolation of MFGM components, including cream washing, ultracentrifugation, and membrane filtration, have been reviewed by Holzmüller and Kulozik (2016). Many of these methods focus on protein components. Several processes have been used in the attempt to recover or enrich PL from MFGM: buttermilk cream churning (Haddadian et al., 2018), ultrafiltration, and supercritical fluid extraction (Spence et al., 2009; Costa et al., 2010). Polar lipids in MFGM have been recovered with the application of chelating zinc salts (Damodaran, 2010; Price et al., 2020). The use of a food-grade solvent, specifically ethanol, for the extraction of PL from dairy products has also shown potential industry application (Castro-Gómez et al., 2016; Price et al., 2018). Price et al. (2018) pumped reconstituted whey protein phospholipid concentrate (WPPC) into hot ethanol, causing lipids to dissolve into the ethanol phase and be recovered after solvent evaporation.

The potential of ethanol as a food-safe solvent for the extraction of polar lipids may offer the dairy industry a new technol- ogy requiring limited or no specialty equipment. The fractional crystallization process allows for the separation of mixtures based on solubility and could potentially isolate polar lipids from triacylglycerol with different solubilities in ethanol. Presented in this study is a novel method for ethanol extraction of polar lipids from WPPC by direct extraction of the powdered product that is commercially available from the dairy industry. Initial investigations into fractional crystallization of milk fat as a potential method for polar lipid purification from ethanol extracts are also described.

Ethanolic extraction was conducted in a reflux apparatus directly mixing WPPC (Hilmar 7500, Hilmar Ingredients) with absolute ethanol. Preliminary trials for this study were used to determine a ratio of dairy powder to extraction solvent that yielded satisfactory results. The amount of solvent for extraction is referred to here in mass equivalents of the solid sample used. A final ratio of 1:20 sample:solvent (wt/wt), or 20 mass equivalents, was used in this study, with $100 \mathrm{~g}$ of WPPC powder for each replicate.

Extraction was completed in 4 cycles; the first cycle used 8 mass equivalents of absolute ethanol, and the next 3 subsequent cycles used 4 mass equivalents of solvent each. The additional solvent used in this first cycle acts to compensate for the volume of solvent required to wet the surface of the solids and allow for a reasonable supernatant layer to form. The extraction mixture was heated under reflux with magnetic stirring just until the first sight of boiling was achieved in $\leq 10 \mathrm{~min}$. At this point, the flask was removed from heat, the boiling was allowed to subside, and the solids were precipitated ( $\sim 3 \mathrm{~min})$.

While still hot, the ethanol solution was decanted away from solids and vacuum filtered through Whatman 1PS silicone-treated filter paper. The flask was returned to the apparatus and refreshed

Department of Food Science and Technology, Oregon State University, Corvallis 97330. *Corresponding author: michael.qian@oregonstate.edu. @ 2021, The Authors. Published by Elsevier Inc. and Fass Inc. on behalf of the American Dairy Science Association ${ }^{\circledR}$. This is an open access article under the CC BY license (http://creativecommons.org/licenses/by/4.0/). Received January 05, 2021. Accepted March 13, 2021. 


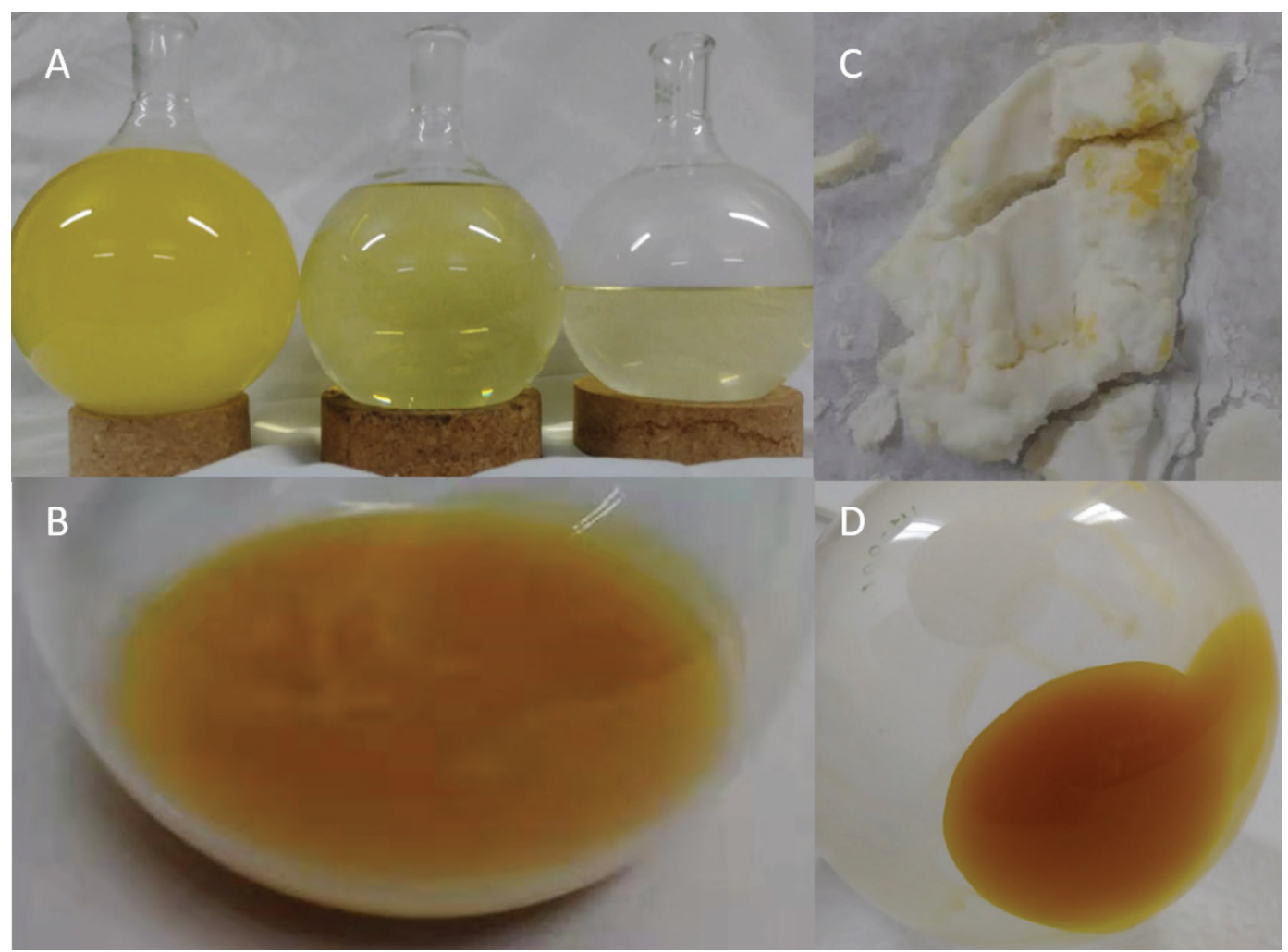

Figure 1. Several steps of the ethanol extraction process. (A) Total volume of ethanol solution recovered during total lipid extraction using 20 mass equivalents. (B) Resulting total lipid extract residue; appears as a solid at room temperature. (C) Recovered crystallized lipids from fractional crystallization process at $15^{\circ} \mathrm{C}$ for $16 \mathrm{~h}$; yellow waxy precipitated solids present in white crystalized lipid solids. (D) Final fractionated PL residue; appears as a viscous liquid at room temperature.

with solvent (4 mass equivalents). This cycle of heating, gravity precipitation, decanting, and new solvent addition was repeated for 4 cycles, and a total of 20 mass equivalents of solvent was used. At the end of the final cycle, the entire reaction mixture was transferred to the filter apparatus, and a vacuum was applied until the solids were dry. The recovered solvent decreased in color intensity as extraction cycles proceeded; this change in color was used as a qualitative indicator that extraction was complete.

The collected filtrate was concentrated by rotary evaporation under a high vacuum until completely dry. The final mass of total lipid extract was measured gravimetrically, and percent lipids recovered was calculated using the manufacturer-provided compositional data. Recovered lipids were transferred to vials for storage and frozen at $-20^{\circ} \mathrm{C}$ until further analysis.

The potential for PL purification and removal of triglyceride content using fractional crystallization was also investigated. Fresh extraction replicates were prepared as described previously until the drying step, where the solution was concentrated to a final mass of $400 \mathrm{~g}$ for crystallization. At this final mass, the resulting solution was at a concentration of approximately $4.75 \%$ lipid $(\mathrm{wt} / \mathrm{wt})$, using the average total lipid extract mass from the previous experiment. Fractional crystallization of the final $4.75 \%$ (wt/wt) solution was done in a circulating water bath at $15^{\circ} \mathrm{C}$ for $16 \mathrm{~h}$.

The crystallization mixture was removed from the water bath, filtered, and rinsed with cold absolute ethanol. The filtrate was dried by rotary evaporation as described previously, and the filtered crystal solids were left to dry on the bench top before both lipid residues were transferred to vials and stored at $-20^{\circ} \mathrm{C}$. The crystallized solids were observed to be white and fluffy with smaller yellow, waxy precipitated solids. The expected PL concentrate residue recovered from the filtrate was an orange-dark yellow viscous liquid at room temperature compared with the total lipid extract, which presented as a solid of similar color (Figure 1).

Phospholipid composition of the total lipid extract and fractionated polar lipids was determined by hydrophilic interaction liquid chromatography HPLC-evaporative light scatter detector (Table 1) using the method published previously (Ferraris et al., 2020). Residues were assumed to be $100 \%$ lipid material; therefore, no further extraction or sample preparation was performed before dilution for analysis. An external standard calibration curve was used for quantitation using polar lipid standards, including phosphatidylinositol (PI), phosphatidylethanolamine (PE), phosphatidylserine (PS), phosphatidylcholine (PC), and sphingomyelin (SM), purchased from Sigma Aldrich.

Fatty acid profiles of all extracts were determined by FAME preparation using methanolic sulfuric acid ( $1 \% \mathrm{vol} / \mathrm{vol})$ according to Christie and Han (2003). Gas chromatography with flame-ionization detection/MS was used for analysis with an IL-111i $(60 \mathrm{~m} \times$ $0.25 \mathrm{~mm}, 0.20 \mu \mathrm{m}$ ) ionic liquid stationary phase capillary column (Sigma Aldrich). An oven program of $100^{\circ} \mathrm{C}$ for $5 \mathrm{~min}, 8^{\circ} \mathrm{C} / \mathrm{min}$ to 
Table 1. Phospholipid composition of total lipid extract and fractionated phospholipid (PL) residues by HPLC-evaporative light scatter detector

\begin{tabular}{|c|c|c|c|c|c|c|}
\hline \multirow[b]{2}{*}{ Item } & \multicolumn{2}{|c|}{ WPPC $^{1}$} & \multicolumn{2}{|c|}{ Total lipid extract ${ }^{2}$} & \multicolumn{2}{|c|}{ Fractionated $\mathrm{PL}^{2}$} \\
\hline & $\%$ PL by mass ${ }^{3}$ & $\%$ of total PL & $\%$ PL by mass ${ }^{4}$ & $\%$ of total PL & $\%$ PL by mass ${ }^{4}$ & $\%$ of total PL \\
\hline Phosphatidylinositol & 0.5 & 5.4 & 1.6 & 4.3 & 0.3 & 0.8 \\
\hline Phosphatidylcholine & 2.2 & 25.7 & 11.8 & 31.2 & 12.5 & 33.1 \\
\hline Sphingomyelin & 1.5 & 16.7 & 8.4 & 22.2 & 10.2 & 27.1 \\
\hline Total & 8.7 & - & 37.7 & - & 38.6 & - \\
\hline
\end{tabular}

${ }^{1}$ Whey protein phospholipid concentrate (WPPC) lipid extracted using the Folch method as described in Ferraris et al. (2020; $\left.n=1\right)$. Crude fat of product was $16.24 \%$ from manufacturer certificate of analysis.

${ }^{2}$ Total lipid extract $(n=3)$ and fractionated PL $(n=3)$ extracts.

${ }^{3}$ Reported as \% PL by mass of WPPC powder.

${ }^{4}$ Reported as \% PL of total lipid extract and fractionated PL residues, respectively.

$180^{\circ} \mathrm{C}, 5^{\circ} \mathrm{C} / \mathrm{min}$ to $260^{\circ} \mathrm{C}$, and hold 5 min was used with $\mathrm{H}_{2}$ carrier at a flow rate of $1.5 \mathrm{~mL} / \mathrm{min}$. The FAME standards were purchased from NuChek Prep. The identifications of FAME standards made by Delmonte et al. (2013) using an IL-111i column $(200 \mathrm{~m})$ in 2-dimensional GC-MS was used for reference in determining the elution order of fatty acids in the CLA region in combination with mass spectral data.

The WPPC used in this study has a reported total fat content of $16.24 \%$ from the manufacturer. The total lipid extract residue recovered represented $19.03 \pm 0.13 \%$ of the original sample mass. The assumption was made in the study that the total lipid extract residue was entirely lipid material, which compared with the manufacturer certificate of analysis yields an extraction recovery of $117 \%$. This discrepancy was not formally investigated here, but it is hypothesized to be the coextraction of other ethanol-soluble components such as water, lactose, and annatto pigments.

Price et al. (2018) showed that higher concentrations of ethanol allow for better separation of lipids from proteins, resulting in higher yields and marginal change lipid recovery over temperatures of $70^{\circ} \mathrm{C}$. The highest recoveries of total PL were reported using $90 \%$ ethanol and $70^{\circ} \mathrm{C}$. This information was used in our experimental design, selecting absolute ethanol as an available prestandardized solvent and ethanol's boiling point as a visual indicator of temperature.

The major PL detected in the ethanol extracts were PE, PC, and SM. This result agrees with the WPPC lipid composition extracted by the Folch method. The fractionated PL residues showed a small increase $(<1 \%)$ in total PL content by mass compared with the total lipid extract. This effect of polar lipid isolation during the fractional crystallization process was not as significant as was hypothesized under the conditions used. Interestingly, PI and PS showed a substantial decrease in concentration in fractionated PL residue after the fractional crystallization process, suggesting cocrystallization with triglyceride into the crystallized lipid residue. The relative percentages of PE and SM were increased substantially. The result indicated that the fractionation process could be used to enrich SM.

Milk fat solubility in ethanol and fractional crystallization in organic solvents are not well reported in the literature. However, the fractional crystallization of milk fat in acetone has been reported using butterfat at a concentration of $10 \%(\mathrm{wt} / \mathrm{vol})$ and temperatures beginning at $15^{\circ} \mathrm{C}$ (Chen and deMan, 1966). Other research us- ing acetone-ethanol mixtures were applied to pili nut oil to create differing melting point fractions at $10 \%(\mathrm{wt} / \mathrm{vol})$ and freezing temperatures (Kakuda et al., 2000). Higher lipid concentrations were not used in this study due to crystal formation observed during rotary evaporation. Further research is needed to determine the effects of concentration and temperature on the crystallization of milk fat in ethanol to assess the utility of fractional crystallization for PL purification.

Fatty acid composition analysis of the ethanol extracts reported a saturated:unsaturated ratio of 1.9, 1.6, and 2.8 for total lipid extract, fractionated PL, and crystallized lipid residues, respectively (Table 2). A higher percentage of SFA were found in total lipid extract and crystallized lipid samples (60.8 and 69.2\%, respectively). In comparison, the fractionated PL residue contained higher levels of MUFA (33.3\%) and PUFA (9.8\%). Two fatty acids appear to fractionate between the PL residue and crystallized lipids, being detected in one fraction and not in the other (C14:1 and C15:0, respectively).

Also important to consider for future applications of the extracted lipids is the final crude composition, including coextracted species such as protein, lactose, ash, water content, and residual ethanol after drying. This method was initially tested using whey protein concentrate $34 \%$ (WPC34), and results are not included here to focus on the potential to recover higher concentrations of PL from MFGM-enriched WPPC products. In short, some additional crystallization believed to be lactose was observed from whey powders with lower protein content (higher lactose content), which will affect future functionality of the extracted lipids from these sources. Application of this method is not limited to WPPC, and results do not suggest a limitation due to protein or fat content.

Moreover, the presence of residual ethanol after drying could affect certain applications of the PL residues. Large quantities of ethanol can serve as a disrupting solvent acting against the emulsifying properties of PL in some food systems and specifically affect freezing properties of the food matrix, such as application of lecithins in ice cream. The major product target for this research was high-protein whey protein isolate consumer products, which often rely on plant-based lecithins to be added during the spraydrying process serving as instantizers. For this specific application of the ethanol-extracted PL residues to spray-dried whey powders, we hypothesize a negligible effect of the trace amount of ethanol 
Table 2. Fatty acid composition of ethanol extracts ${ }^{1}$

\begin{tabular}{|c|c|c|c|}
\hline Fatty acid ${ }^{2}$ & $\begin{array}{l}\text { Total lipid } \\
\text { extract }\end{array}$ & $\begin{array}{l}\text { Fractionated } \\
\text { phospholipids }\end{array}$ & $\begin{array}{l}\text { Crystallized } \\
\text { lipid }\end{array}$ \\
\hline C4:0 & 0.6 & 0.6 & 0.2 \\
\hline $\mathrm{C} 6: 0$ & 0.5 & 0.6 & 0.1 \\
\hline C8:0 & 0.4 & 0.5 & 0.2 \\
\hline C10:0 & 1.5 & 1.6 & 1.0 \\
\hline C12:0 & 2.2 & 2.2 & 1.8 \\
\hline C14:0 & 8.1 & 8.2 & 7.8 \\
\hline C15:0 & 0.4 & $\mathrm{ND}^{3}$ & 1.0 \\
\hline C14:1 & 0.8 & 1.6 & ND \\
\hline C16:0 & 28.8 & 28.5 & 29.9 \\
\hline C16:1 & 0.7 & 1.0 & 0.5 \\
\hline $\mathrm{C} 17: 0$ & 0.9 & 0.7 & 0.9 \\
\hline C18:0 & 15.5 & 11.7 & 25.1 \\
\hline C18:1 & 27.5 & 29.7 & 21.5 \\
\hline C18:2 & 7.4 & 7.9 & 5.9 \\
\hline C20:1 & 0.4 & 0.4 & 0.5 \\
\hline C18:3 (CLA) & 0.3 & 0.4 & 0.2 \\
\hline$C 20: 2$ & 0.2 & 0.4 & 0.2 \\
\hline $\mathrm{C} 22: 0$ & 1.1 & 1.4 & 1.0 \\
\hline C22:1 & 0.3 & 0.4 & 0.7 \\
\hline$C 20: 3+C 20: 4^{4}$ & 0.8 & 0.8 & 0.7 \\
\hline C24:0 & 0.7 & 0.9 & 0.4 \\
\hline C24:1 & 0.1 & 0.2 & 0.1 \\
\hline C20:5 & 0.1 & 0.1 & 0.1 \\
\hline C22:4 & 0.2 & 0.2 & 0.3 \\
\hline$C 22: 5 n-3$ & 0.2 & 0.2 & 0.3 \\
\hline Total SFA (\%) & 60.8 & 56.9 & 69.2 \\
\hline Total UFA (\%) & 31.8 & 35.2 & 24.9 \\
\hline SFA:UFA ratio & 1.9 & 1.6 & 2.8 \\
\hline MUFA (\%) & 29.9 & 33.3 & 23.2 \\
\hline PUFA (\%) & 9.3 & 9.8 & 7.6 \\
\hline
\end{tabular}

${ }^{1}$ Individual fatty acid values reported on weight percentage (wt \%) basis of total fatty acids.

${ }^{2}$ Fatty acids listed in chromatographic elution order on an IL-111i ionic liquid stationary phase capillary column (Sigma Aldrich).

${ }^{3} \mathrm{ND}=$ not detected.

${ }^{4}$ Fatty acids C20:3 and C20:4 could not be resolved on 60-m column.

present in the dried lipids on the success of the instantization and drying process. Ethanol present in the PL residue would be expected to evaporate along with water in the spray drier and is not expected to remain in the final product.

Overall, the ethanol extraction method of polar lipids directly from powdered WPPC was successful while avoiding specialized equipment and considerable dilution of other food-grade solvent extraction methods. Further investigations into the presence of other coextracted whey components would allow for increased yield accuracies to assist in PL recovery optimization. Although the conditions used for fractional crystallization of the total lipid extract have yet to support the current utility of crystal purification of polar lipids in ethanol ( $<1 \%$ increase in total PL), the research proved the concept of ethanol extraction and fractional crystallization for PL extraction and SM enrichment.

\section{References}

Castro-Gómez, P., L. M. Rodríguez-Alcalá, K. M. Monteiro, A. L. T. G. Ruiz, J. E. Carvalho, and J. Fontecha. 2016. Antiproliferative activity of buttermilk lipid fractions isolated using food grade and non-food grade solvents on human cancer cell lines. Food Chem. 212:695-702. https://doi.org/10 .1016/j.foodchem.2016.06.030.
Chen, P. C., and J. M. deMan. 1966. Composition of milk fat fractions obtained by fractional crystallization from acetone. J. Dairy Sci. 49:612-616. https: //doi.org/10.3168/jds.S0022-0302(66)87917-1.

Christie, W. W., and X. Han. 2003. Preparation of derivatives of fatty acids. Lipid Anal. 3:217.

Cilla, A., K. Diego Quintaes, R. Barberá, and A. Alegría. 2016. Phospholipids in human milk and infant formulas: Benefits and needs for correct infant nutrition. Crit. Rev. Food Sci. Nutr. 56:1880-1892. https://doi.org/10 $.1080 / 10408398.2013 .803951$.

Costa, M. R., X. E. Elias-Argote, R. Jiménez-Flores, and M. L. Gigante. 2010. Use of ultrafiltration and supercritical fluid extraction to obtain a whey buttermilk powder enriched in milk fat globule membrane phospholipids. Int. Dairy J. 20:598-602. https://doi.org/10.1016/j.idairyj.2010.03.006.

Damodaran, S. 2010. Zinc-induced precipitation of milk fat globule membranes: A simple method for the preparation of fat-free whey protein isolate. J. Agric. Food Chem. 58:11052-11057. https://doi.org/10.1021/jf101664j.

Delmonte, P., A. R. Fardin-Kia, and J. I. Rader. 2013. Separation of fatty acid methyl esters by GC-online hydrogenation $\times$ GC. Anal. Chem. 85:15171524. https://doi.org/10.1021/ac302707z.

Ferraris, Q., J. Hale, E. Teigland, A. Rao, and M. C. Qian. 2020. Phospholipid analysis in whey protein products using hydrophilic interaction highperformance liquid chromatography-evaporative light-scattering detection in an industry setting. J. Dairy Sci. 103:11079-11085. https://doi.org/10 $.3168 /$ jds.2020-18687.

Haddadian, Z., G. T. Eyres, P. Bremer, and D. W. Everett. 2018. Polar lipid composition of the milk fat globule membrane in buttermilk made using various cream churning conditions or isolated from commercial samples. Int. Dairy J. 81:138-142. https://doi.org/10.1016/j.idairyj.2018.01.012.

Holzmüller, W., and U. Kulozik. 2016. Technical difficulties and future challenges in isolating membrane material from milk fat globules in industrial settings - A critical review. Int. Dairy J. 61:51-66. https://doi.org/10.1016/ j.idairyj.2016.03.013.

Kakuda, Y., F. Jahaniaval, M. F. Marcone, L. Montevirgen, Q. Montevirgen, and J. Umali. 2000. Characterization of pili nut (Canarium ovatum) oil: Fatty acid and triacylglycerol composition and physicochemical properties. J. Am. Oil Chem. Soc. 77:991-997. https://doi.org/10.1007/s11746 -000-0156-8.

Lopez, C., V. Briard-Bion, and O. Ménard. 2014. Polar lipids, sphingomyelin and long-chain unsaturated fatty acids from the milk fat globule membrane are increased in milks produced by cows fed fresh pasture based diet during spring. Food Res. Int. 58:59-68. https://doi.org/10.1016/j.foodres.2014.01 .049 .

Price, N., T. Fei, S. Clark, and T. Wang. 2018. Extraction of phospholipids from a dairy by-product (whey protein phospholipid concentrate) using ethanol. J. Dairy Sci. 101:8778-8787. https://doi.org/10.3168/jds.2018-14950.

Price, N., T. Fei, S. Clark, and T. Wang. 2020. Application of zinc and calcium acetate to precipitate milk fat globule membrane components from a dairy by-product. J. Dairy Sci. 103:1303-1314. https://doi.org/10.3168/jds.2019 -16892 .

Singh, H., and S. Gallier. 2017. Nature's complex emulsion: The fat globules of milk. Food Hydrocoll. 68:81-89. https://doi.org/10.1016/j.foodhyd.2016 10.011.

Spence, A. J., R. Jimenez-Flores, M. Qian, and L. Goddik. 2009. Phospholipid enrichment in sweet and whey cream buttermilk powders using supercritical fluid extraction. J. Dairy Sci. 92:2373-2381. https://doi.org/10.3168/ jds.2008-1534.

Tanaka, K., M. Hosozawa, N. Kudo, N. Yoshikawa, K. Hisata, H. Shoji, K. Shinohara, and T. Shimizu. 2013. The pilot study: Sphingomyelin-fortified milk has a positive association with the neurobehavioural development of very low birth weight infants during infancy, randomized control trial. Brain Dev. 35:45-52. https://doi.org/10.1016/j.braindev.2012.03.004.

Vors, C., L. Joumard-Cubizolles, M. Lecomte, E. Combe, L. Ouchchane, J. Drai, K. Raynal, F. Joffre, L. Meiller, M. Le Barz, P. Gaborit, A. Caille, M. Sothier, C. Domingues-Faria, A. Blot, A. Wauquier, E. Blond, V. Sauvinet, G. Gésan-Guiziou, J.-P. Bodin, P. Moulin, D. Cheillan, H. Vidal, B Morio, E. Cotte, F. Morel-Laporte, M. Laville, A. Bernalier-Donadille, S. Lambert-Porcheron, C. Malpuech-Brugère, and M.-C. Michalski. 2019. Milk polar lipids reduce lipid cardiovascular risk factors in overweight postmenopausal women: Towards a gut sphingomyelin-cholesterol interplay. Gut 69:487-501. https://doi.org/10.1136/gutjnl-2018-318155. 


\section{Notes}

Quintin Ferraris @ https://orcid.org/0000-0003-0472-5837

Michael C. Qian $\odot$ https://orcid.org/0000-0003-4694-6961

The authors acknowledge Building University-Industry through Learning and Discovery in Dairy (BUILD-Dairy), the Western Dairy Center (Logan UT), and Agropur (Eden Prairie, MN) for their support of this research. The authors thank Hilmar Cheese Company (Hilmar, CA) for donating the WPPC samples.

The authors have not stated any conflicts of interest. 